\title{
Assessing the ability of integrated reporting to meet the requirements of stakeholders \\ cX
}

\section{Osman Mohamed Yassin Farag, Osama Ahmed Jamal Hilali, Ahmed Hassan Ahmed and Ali Ahmed Gad}

Faculty of Commerce, South Valley University

\begin{abstract}
:
The study aims mainly to assess the capacity of integrated reporting to meet the requirements of the stakeholders, in order to achieve this goal, the study has developed an evaluation strategy of three axes, the first focused on assessing the capacity of these reports to disclose the values achieved by the stakeholders, while the second focused on the assessing of the extent to regulate the content of these reports, Finally, the third axis focused on the ability of these reports on the link between financial and non-financial information to achieve integration between information, the study has also explored the views of the three categories of dealers with the reports issued by Companies registered in the Egyptian Stock Exchange, they are: the Auditors and financial analysts and academics in universities, by distribution 150 list of the survey to these groups equally, the study found that the integrated reporting may be able to meet the needs of some of the stakeholders of the information, it also has several aspects of the shortcomings in the organization where these reports are still long and incomparable, as well as limited capacity on the link between financial and nonfinancial information in such a way which achieve integration of information.
\end{abstract}

Keywords: integrated reporting, stakeholders

\section{Citation}

Farag et.al., Requirements of Electronic Management in the Management of Kindergarten Institutions. SVU-Journal of abstract 2019, Vol.1: pp23 (retrieved from the Journal of Educational Sciences; 2018, No.35; pp .....)

Copyright: Publisher South Valley University.

This is an open-access article distributed under the terms of the creative commons attribution license, which permits unrestricted use, distribution and reproduction in any medium provided the original author and source are created. 